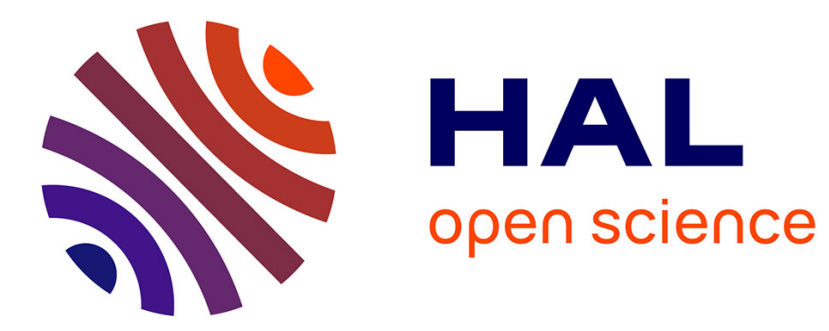

\title{
The origins of polarimetric image contrast between healthy and cancerous human colon tissue
}

Tatiana Novikova, Angelo Pierangelo, Sandeep Manhas, Abdelali Benali, Pierre Validire, Brice Gayet, Antonello de Martino

\section{- To cite this version:}

Tatiana Novikova, Angelo Pierangelo, Sandeep Manhas, Abdelali Benali, Pierre Validire, et al.. The origins of polarimetric image contrast between healthy and cancerous human colon tissue. Applied Physics Letters, 2013, 102, pp.241103. 10.1063/1.4811414 . hal-00904992

\section{HAL Id: hal-00904992 https://hal.science/hal-00904992}

Submitted on 15 Nov 2013

HAL is a multi-disciplinary open access archive for the deposit and dissemination of scientific research documents, whether they are published or not. The documents may come from teaching and research institutions in France or abroad, or from public or private research centers.
L'archive ouverte pluridisciplinaire HAL, est destinée au dépôt et à la diffusion de documents scientifiques de niveau recherche, publiés ou non, émanant des établissements d'enseignement et de recherche français ou étrangers, des laboratoires publics ou privés. 


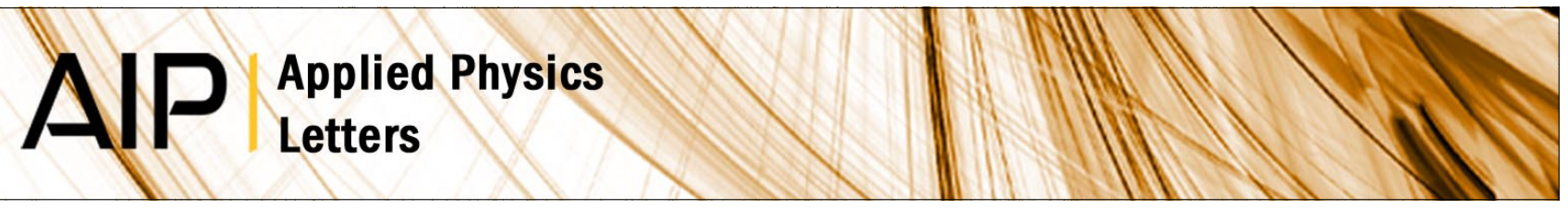

The origins of polarimetric image contrast between healthy and cancerous human colon tissue

T. Novikova, A. Pierangelo, S. Manhas, A. Benali, P. Validire et al.

Citation: Appl. Phys. Lett. 102, 241103 (2013); doi: 10.1063/1.4811414

View online: http://dx.doi.org/10.1063/1.4811414

View Table of Contents: http://apl.aip.org/resource/1/APPLAB/v102/i24

Published by the AIP Publishing LLC.

Additional information on Appl. Phys. Lett.

Journal Homepage: http://apl.aip.org/

Journal Information: http://apl.aip.org/about/about_the_journal

Top downloads: http://apl.aip.org/features/most_downloaded

Information for Authors: http://apl.aip.org/authors

\section{ADVERTISEMENT}

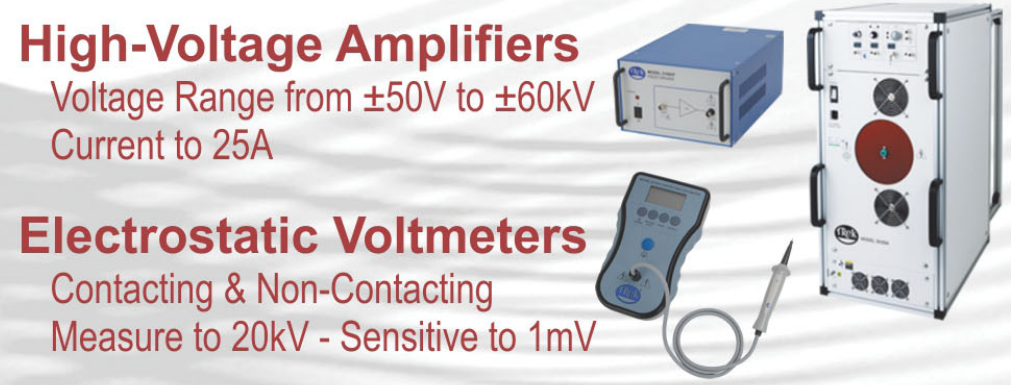

ENABLING RESEARCH AND INNOVATION IN DIELECTRICS, ELECTROSTATICS, MATERIALS, PLASMAS AND PIEZOS

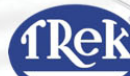

WWW.trekinc.com 


\title{
The origins of polarimetric image contrast between healthy and cancerous human colon tissue
}

\author{
T. Novikova, ${ }^{1, a)}$ A. Pierangelo, ${ }^{1}$ S. Manhas, ${ }^{1}$ A. Benali, ${ }^{2}$ P. Validire, ${ }^{2}$ B. Gayet,${ }^{3}$ \\ and A. De Martino ${ }^{1}$ \\ ${ }^{1}$ LPICM, Ecole polytechnique, CNRS, Palaiseau 91128 , France \\ ${ }^{2}$ Département d'Anatomopathologie de l'Institut Mutualiste Montsouris, 42 Bd Jourdan, 75014 Paris, France \\ ${ }^{3}$ Département médico-chirurgical de pathologie digestive de l'Institut Mutualiste Montsouris, \\ 42 Bd Jourdan, 75014 Paris, France
}

(Received 8 April 2013; accepted 2 June 2013; published online 17 June 2013)

\begin{abstract}
Experimentally measured spectral Mueller matrix images of ex vivo human colon tissue revealed the contrast enhancement between healthy and cancerous zones of colon specimen compared to unpolarized intensity images. Cancer development starts with abnormal changes which being not yet visible macroscopically may alter the polarization of reflected light. We have shown with experiments and modeling that light scattering by small (sub wavelength) scatterers and light absorption (mainly due to blood hemoglobin) are the key factors for observed polarimetric image contrast. These findings can pave the way for the alternative optical technique for the monitoring and early detection of cancer. (C) 2013 AIP Publishing LLC. [http://dx.doi.org/10.1063/1.4811414]
\end{abstract}

Being fast and minimally invasive, optical techniques are attracting increasing interest in biomedical diagnostics. Confocal microscopy and optical coherence tomography (OCT), among others, are well suited to detailed morphological characterization of small $\left(\mathrm{mm}^{2}\right)$ samples. On the other hand, for larger samples, microscopic imaging may be less adequate compared to diffuse reflectance spectroscopy or Mueller polarimetry macroscopic imaging. The images of healthy and cancerous human colon tissue were acquired with multispectral imaging Mueller polarimeter ${ }^{1,2}$ operating in backscattering configuration. The measurements were performed on fresh colon specimens in the spectral range of $500-700 \mathrm{~nm}$ with a step of $50 \mathrm{~nm}$. The excised pieces were opened along the axis of the colon tube and fixed on a plane support. We used a telecentric illumination system, and the field of view of our instrument was varied between 2 and $7 \mathrm{~cm}$. Measured Mueller matrices ${ }^{3}$ were normalized by total intensity values (element $\mathrm{M}_{11}$ ). In this work, we used the same convention as in Ref. 1, for which the Mueller matrix of a mirror at normal incidence is a unity matrix. With respect to the most commonly used convention the sign of the third and fourth rows is reversed.

We have studied the polarimetric images of 20 samples, all from different patients, containing both healthy and diseased zones. The presence of malignancy (Liberkühn adenocarcinoma) was further confirmed by anatomopathology analysis of corresponding histological plates. The Mueller matrices of human colon were basically diagonal. ${ }^{2}$ Thus, colon tissue only partially depolarized both linearly and circularly polarized incident light, manifesting neither significant diattenuation nor retardance. While absolute values of $M_{22}$ and $M_{44}$ elements slightly varied for different patients, the typical trends of spectral dependence of $M_{22}$ and $M_{44}$ elements for cancerous human colon tissue at early stage of

\footnotetext{
a) Author to whom correspondence should be addressed. Electronic mail: tatiana.novikova@polytechnique.edu
}

cancer development and healthy colon tissue (shown on Fig. 1) were always the same. The plotted values of spectral Mueller matrix coefficients were averaged over the pixels corresponding to healthy and cancerous zones, respectively.

The decrease of $M_{22}$ and $M_{44}$ values with wavelength is correlated with the decrease of absorption by blood hemoglobin, which is the main source of the light absorption in the visible wavelength range. ${ }^{4}$ Thus, the increase of light penetration depth enhances the scattering and leads to a larger depolarization of backscattered light for both healthy and cancerous tissues in red part of the spectrum.

At all wavelengths we have observed that the diseased zone was less depolarizing compared to the healthy zone for both linearly $\left(M_{22}, M_{33}\right.$ elements $)$ and circularly $\left(M_{44}\right.$ element) polarized light

$$
\left|M_{i i}\right|^{\text {cancer }}>\left|M_{i i}\right|^{\text {healthy }}, \quad i=2-4 .
$$

The following relations on $M_{22}, M_{33}$, and $M_{44}$ elements of the Mueller matrix were always hold for both healthy and cancerous zones of human colon

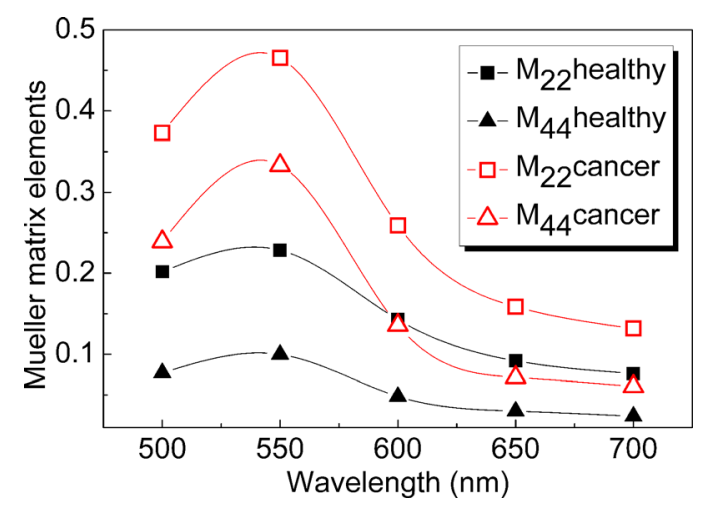

FIG. 1. Experimental spectral dependence of diagonal elements $\mathrm{M}_{22}$ (squares) and $\mathrm{M}_{44}$ (triangles) averaged over healthy (bold symbols) and cancerous (open symbols) zones of colon specimen. 


$$
\begin{gathered}
\left|M_{22}\right|=\left|M_{33}\right|>\left|M_{44}\right|, \\
M_{44}>0 .
\end{gathered}
$$

Many experimental and theoretical studies have related the scattering properties of real biological tissue to the scattering on cell nuclei with diameter of several microns which is much larger than the wavelength of visible probing light. Since the histology confirms that development of epithelial cell cancer is typically accompanied by the increase of cell nuclei diameter (up to more than $10 \mu \mathrm{m}$ ), the early cancerous changes of the tissue were often modeled by further increase of the effective scatterer size in the optical model of tissue. Thick biological tissue of colon is a multiple scattering medium in a visible wavelength range. Hence, better preservation of linear compared to circular polarization of backscattered light (see Eq. (2a)) observed in our experiments is due to the fact that detected light was mainly scattered by the particles that are small compared to the wavelength of measurements. ${ }^{5,6}$

In some studies ${ }^{7-9}$ the unpolarized diffuse reflectance spectra of healthy and abnormal colon were measured and fitted either with Monte Carlo method ${ }^{7,8}$ or analytical diffusion theory $\operatorname{model}^{9}$ for the scattering medium. In both cases the calculated average value of hemoglobin concentration (consequently, coefficient of absorption) was higher for abnormal colon zone compared to normal tissue. The calculated density of scatterers decreased for diseased zone. Conversely, the effective scatterer size within cancerous zone either decreased or increased depending on the model. Probably, the parameters of optical model were highly correlated. Thus, detection of abnormal colon zones based on the predictions of indirect model-based techniques may be somehow ambiguous. Clearly, the question arises: may the spectral measurements of complete Mueller matrix have some benefits compared to unpolarized intensity measurements or partial polarimetric measurements? $?^{7-10}$

To address this question we took the set of optimal parameters of detailed multilayer colon optical $\operatorname{model}^{7}$ (see Table I), then simulated corresponding multispectral Mueller matrices with polarized Monte Carlo method, ${ }^{2}$ and compared them with our measured Mueller matrices. The coefficient of absorption $\mu_{\mathrm{a}}$ was defined as

$$
\mu_{\mathrm{a}}(\lambda)=V \ln 10 C_{H b}\left(\alpha \varepsilon_{H b O_{2}}(\lambda)+(1-\alpha) \varepsilon_{H b}(\lambda)\right),
$$

where $\lambda$ is the wavelength, $C_{\mathrm{Hb}}$ is the concentration of hemoglobin per unit volume of blood ( $120 \mathrm{~g} / \mathrm{l}$ for colon tissue), $\varepsilon_{\mathrm{HbO} 2}$ and $\varepsilon_{\mathrm{Hb}}$ are the molar extinction coefficients of oxyhemoglobin and hemoglobin, respectively. ${ }^{4}$

TABLE I. Parameters of optical model of colon.

\begin{tabular}{lccccc}
\hline \hline Layer & $V(\%)^{\mathrm{a}}$ & $\alpha(\%)^{\mathrm{b}}$ & $d(\mu \mathrm{m})^{\mathrm{c}}$ & $V_{\mathrm{sc}}(\%)^{\mathrm{d}}$ & $h(\mu \mathrm{m})^{\mathrm{e}}$ \\
\hline Mucosa & 3.5 & 70.3 & 0.3365 & 16.8 & 446 \\
Submucosa & 20 & 75 & 3.5 & 50 & 700 \\
\hline \hline
\end{tabular}

${ }^{\mathrm{a}} V$ is the volume fraction of blood.

${ }^{\mathrm{b}} \alpha$ is the saturation of hemoglobin by oxygen.

${ }^{\mathrm{c}} d$ is the diameter of scatterers.

${ }^{\mathrm{d}} V_{\mathrm{sc}}$ is the volume fraction of scatterers.

${ }^{\mathrm{e}} h$ is the thickness of the layer.
We started with the calculations of backscattering Mueller matrix at $\lambda=550 \mathrm{~nm}$ for the model of healthy colon tissue described above. With volume fraction of mucosa scatterers fixed at $16.8 \%$ (resulting scattering coefficient $\mu_{\mathrm{s}}^{\mathrm{m}}=285.6 \mathrm{~cm}^{-1}$ ) the simulated value of element $M_{44}$ was negative (see Fig. 2), while it always remained positive in our measurements of colon tissue (see Eq. (2b)).

Both light scattering and absorption affect the values of Mueller matrix coefficients. To understand their impact we performed the parametric studies, varying the volume fraction of mucosa scatterers (or scattering coefficient $\mu_{\mathrm{s}}^{\mathrm{m}}$ ) for two different values of blood volume fraction within mucosa. At $V^{\mathrm{m}}=3.5 \%$ the absorption coefficient $\mu_{\mathrm{a}}^{\mathrm{m}}$ was equal to $8.7 \mathrm{~cm}^{-1}$. The increase of mucosa blood volume fraction up to $20 \%$ resulted in absorption coefficient $\mu_{\mathrm{a}}^{\mathrm{m}}=49.5 \mathrm{~cm}^{-1}$ (see Eq. (3)).

As expected, the values of both $M_{22}$ and $M_{44}$ elements, and consequently the polarization of backscattered light increased with the decrease of volume fraction of mucosa scatterers. Indeed, within less dense scattering medium the backscattered light undergoes less collisions, thus preserving better its initial polarization state (either linear or circular). Moreover, the value of $M_{44}$ element became positive when density of mucosa scatterers dropped below some critical value. This change of sign combined with the decrease of total reflectivity $M_{11}$ (not shown in Fig. 2) indicated that contribution of multiple scattering to the detected backscattered signal significantly decreased. The increase of mucosa absorption coefficient (Fig. 2, open symbols) led to increase of the values of both $M_{22}$ and $M_{44}$ elements. At fixed mucosa scattering coefficient $\mu_{\mathrm{s}} \mathrm{m}$ the degree of polarization of backscattered light was higher in case of strong absorption because less photons with long paths (consequently, having more collisions and losing their initial polarization) can reach the detector.

At the same mucosa blood volume fraction $V^{\mathrm{m}}=3.5 \%$ the absorption coefficient of mucosa $\mu_{\mathrm{a}}^{\mathrm{m}}$ dropped significantly with wavelength increase: $\mu_{\mathrm{a}}^{\mathrm{m}}(650 \mathrm{~nm})=0.26 \mathrm{~cm}^{-1}$ versus $\mu_{\mathrm{a}}^{\mathrm{m}}(550 \mathrm{~nm})=8.7 \mathrm{~cm}^{-1}$. Hence the light penetrated deeper compared to shorter wavelength. The contribution of scattering

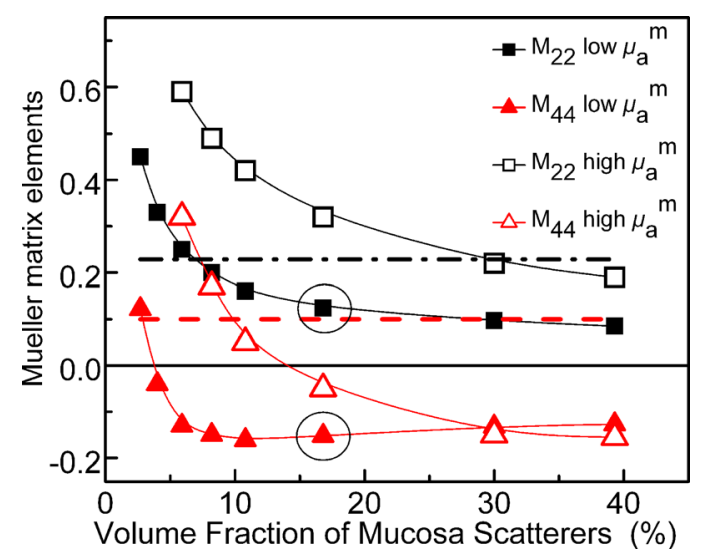

FIG. 2. Simulated backscattering Mueller matrix elements $\mathrm{M}_{22}$ (squares) and $\mathrm{M}_{44}$ (triangles) versus different values of mucosa $\mathrm{V}_{\mathrm{sc}}{ }^{\mathrm{m}}\left(\mu_{\mathrm{s}}^{\mathrm{m}}=100-513 \mathrm{~cm}^{-1}\right)$ at low $\left(8.7 \mathrm{~cm}^{-1}\right)$ and high $\left(49.5 \mathrm{~cm}^{-1}\right)$ values of absorption coefficient $\mu_{\mathrm{a}}{ }^{\mathrm{m}}$ corresponding to different volume fraction of blood within mucosa. Values of $\mathrm{M}_{22}$ and $\mathrm{M}_{44}$ calculated for data set from Table I are shown by large circles. Typical measured values of $\mathrm{M}_{22}$ and $\mathrm{M}_{44}$ for healthy colon tissue are shown with dashed-dotted and dashed lines, respectively. 


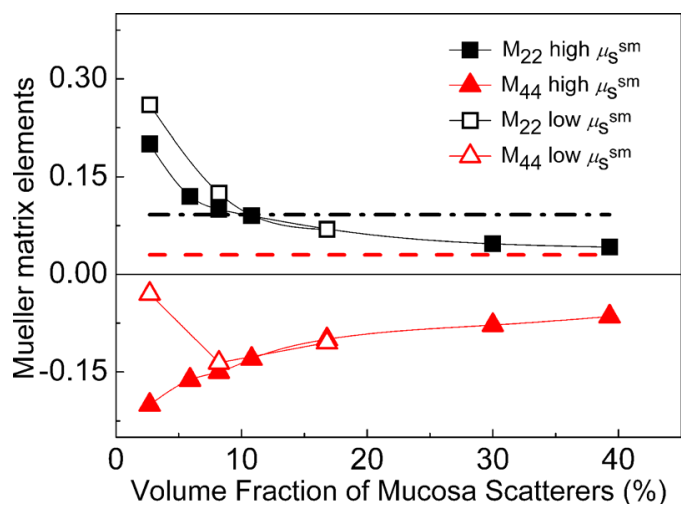

FIG. 3. Simulated backscattering Mueller matrix elements $\mathbf{M}_{22}$ (squares) and $\mathrm{M}_{44}$ (triangles) at $\lambda=650 \mathrm{~nm}$ for different values of mucosa $\mathrm{V}_{\mathrm{sc}}{ }^{\mathrm{m}}$ $\left(\mu_{\mathrm{s}}^{\mathrm{m}}=65-439 \mathrm{~cm}^{-1}\right)$ and fixed value of $\mu_{\mathrm{a}}{ }^{\mathrm{m}}=0.26 \mathrm{~cm}^{-1}$. Typical measured values of $\mathrm{M}_{22}$ and $\mathrm{M}_{44}$ for healthy colon tissue are shown with dotted and dashed lines, respectively. Solid and open symbols correspond to different values of submucosa scattering coefficient $\mu_{\mathrm{sc}}^{\mathrm{sm}}$.

from underlying submucosa layer to backscattered detected signal became significant. As a consequence, it was not enough to decrease only the volume fraction of mucosa scatterers in order to get the positive values of simulated $M_{44}$ element (see Fig. 3).

We had to decrease significantly the volume fraction of scatterers within submucosa layer $\left(\mu_{s c}{ }^{\mathrm{sm}}=121 \mathrm{~cm}^{-1}\right.$ compared to initial $\left.\mu_{s c}^{\mathrm{sm}}=667.8 \mathrm{~cm}^{-1}\right)$ to reproduce the same trend for $M_{44}$ values (see Fig. 3, open triangles) at $650 \mathrm{~nm}$ as at short wavelength of $550 \mathrm{~nm}$. But even the largest value of $M_{44}$ element still remained negative. Further reduction of submucosa scattering coefficient $\mu_{s c}{ }^{\text {sm }}$ was needed to obtain the positive value of $M_{44}$ at low volume fraction of mucosa scatterers. Thus, qualitative polarimetric analysis of optical model of healthy colon ${ }^{8}$ demonstrated that both mucosa and submucosa scattering coefficients were overestimated and/or mucosa absorption coefficient was underestimated.

Histologically confirmed increase of cellular density and size of the nuclei within cancerous tissue is sometimes considered to be the main reason for the changes of polarimetric properties of the tissue. The typical size of healthy nuclei is about several microns, which is much larger then the wavelength of probing light in our experiments. We kept the set of parameters from Table I and increased the diameter of mucosa scatterers up to $8 \mu \mathrm{m}$, modeling the growth of abnormal cells (see Fig. 4). The absorption coefficient of mucosa $\mu_{\mathrm{a}}^{\mathrm{m}}(550 \mathrm{~nm})$ was kept at $8.7 \mathrm{~cm}^{-1}$.

In our simulations the linear polarization of the backscattered light (Fig. 4(a), element $M_{22}$ ) had slightly dropped with mucosa scatterer size increase. Contrary to that the experimentally measured values of $M_{22}$ were always larger for abnormal zones at initial stage (when cancer did not penetrated into deeper layers) compared to the healthy zones. ${ }^{11,12}$ The simulated circular polarization of the backscattered light (Fig. 4(b), element $M_{44}$ ) demonstrated an opposite trend with mucosa scatterers size increase, compared to experimentally measured values. For large mucosa scatterers $(d=8 \mu \mathrm{m}$, cancerous tissue model) the simulated value of $M_{44}$ element again had an opposite sign compared to values of $M_{44}$ element measured within the cancerous zone. It proved that polarimetric signature of cancerous zone in

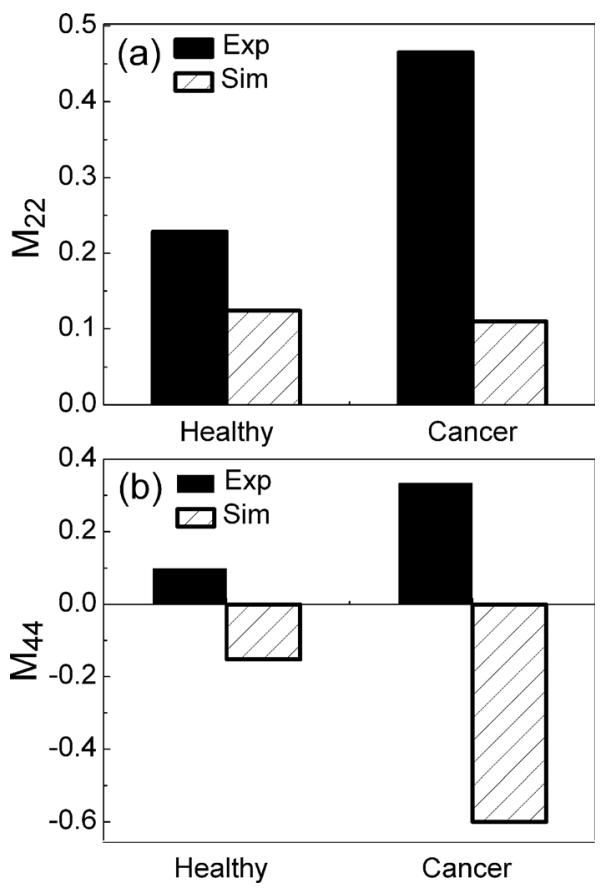

FIG. 4. Values of backscattering Mueller matrix elements (a) $M_{22}$ and (b) $M_{44}$ measured at wavelength $550 \mathrm{~nm}$ for both healthy and cancerous colon tissue (solid columns). Simulated values of $\mathrm{M}_{22}$ and $\mathrm{M}_{44}$ (dashed columns) with $\mu_{\mathrm{sc}}^{\mathrm{m}}=285.1 \mathrm{~cm}^{-1}$ (healthy tissue model, small scatterers), $\mu_{\mathrm{sc}}^{\mathrm{m}}=515.1 \mathrm{~cm}^{-1}$ (cancerous tissue model, large scatterers).

backscattering configuration is not defined by the scattering on large nuclei of abnormal cells.

Images of ex vivo colon specimen taken with multispectral Mueller matrix imaging polarimeter demonstrated the enhancement of polarimetric image contrast between healthy and cancerous zones. For both zones the degree of linear polarization of backscattered light was higher compared to circular polarization. Measured values of $M_{44}$ element were always positive for human colon specimen. The depolarization of backscattered light (linearly or circularly polarized) was larger for healthy tissue compared to cancerous zones at early stage.

Monte Carlo simulations of polarized light transport within the colon tissue demonstrated that light is mainly backscattering on small (compared to wavelength) scatterers. The increase of scattering reduced the polarization of backscattering light while the increase of absorption had an opposite effect on it. The better preservation of polarization of light backscattering from cancerous zone could be explained by both dumping of scattering because of the break of healthy tissue ordered structure and increase of absorption due to enhanced vascularization of the tumor zone at the early stage of cancer development. Thus, image contrast enhancement with multispectral imaging Mueller polarimetry makes it a promising technique for cancer monitoring, detection, and staging. ${ }^{11,12}$

This study was supported by funding from INCa (Institut National $\mathrm{du}$ Cancer) and Cancéropôle under Contract No. 2012-GYN-01-EP-1.

${ }^{1}$ B. Laude-Boulesteix, A. De Martino, B. Drévillon, and L. Schwartz, Appl. Opt. 43, 2824 (2004).

${ }^{2}$ M. R. Antonelli, A. Pierangelo, T. Novikova, P. Validire, A. Benali, B. Gayet, and A. De Martino, Opt. Express 18, 10200 (2010). 
${ }^{3}$ S. Huard, Polarization of Light (Wiley, New York, 1997).

${ }^{4}$ See supplementary material at http://dx.doi.org/10.1063/1.4811414 for hemoglobin absorption spectra.

${ }^{5}$ D. Bicout, C. Brosseau, A. S. Martinez, and J. M. Schmitt, Phys. Rev. E 49, 1767 (1994).

${ }^{6}$ M.-R. Antonelli, A. Pierangelo, T. Novikova, P. Validire, A. Benali, B. Gayet, and A. De Martino, Biomed. Opt. Express 2, 1836 (2011).

${ }^{7}$ D. Rowe and E. Claridge, Proc. SPIE 5745, 127 (2005).

${ }^{8}$ D. Rowe and E. Claridge, Phys. Med. Biol. 50, 1071 (2005).

${ }^{9}$ G. Zonios, L. T. Perelman, V. Backman, R. Manoharan, M. Fitzmaurice, J. Van Dam, and M. S. Feld, Appl. Opt. 38, 6628 (1999).
${ }^{10}$ V. Backman, M. B. Wallace, L. T. Perelman, J. T. Arendt, R. Gurjar, M. G. Müller, Q. Zhang, G. Zonios, E. Kline, T. McGillican, S. Shapshay, T. Valdez, K. Badizadegan, J. M. Crawford, M. Fitzmaurice, S. Kabani, H. S. Levin, M. Seiler, R. R. Dasari, I. Itzkan, J. Van Dam, and M. S. Feld, Nature (London) 406, 35 (2000).

${ }^{11}$ A. Pierangelo, A. Benali, M.-R. Antonelli, T. Novikova, P. Validire, B. Gayet, and A. De Martino, Opt. Express 19, 1582 (2011).

${ }^{12}$ A. Pierangelo, S. Manhas, A. Benali, M.-R. Antonelli, T. Novikova, P. Validire, B. Gayet, and A. De Martino, Proc. SPIE 7895, 78950E (2011). 